\title{
Emotions and leadership. Reasons and impact of emotions in organizational context
}

\author{
Meike Siebert-Adzic \\ Department of Human and Organizational Engineering and System Design, University of Kassel, Mechanical \\ Engineering, 34132 Kassel, siebert-adzic@uni-kassel.de, Germany
}

\begin{abstract}
Emotions as reasons for dissatisfaction, decreasing job performance or physical and mental strain at work are becoming more and more important. Especially psycho-social interactions with conflicts between employees and managers, caused by leadership behavior, as a source of negative emotions are relevant in this context [1]. Which relevance emotions can have in order to influence human behavior and in order to influence work climate will be demonstrated by two qualitative field surveys in the automotive and the energy sector. The study in the energy sector will explain which leadership behavior fosters an improved employee behavior concerning occupational health and safety. A second study in the automotive industry shows that leadership behavior which causes positive emotions is essential for successful teamwork.
\end{abstract}

Keywords: leadership, emotion, psycho-social interaction

\section{Introduction}

The number of mental illnesses in Germany has been rising in the last years from 3,8 cases in 1986 to 12,8 cases per 1000 assured people in 2008 [2]. Moreover the average duration of disease runs up to 22,6 days per case [3]. This underlines the importance of mental strain factors.

In this coherence, emotions as psycho-social strain factors, caused by superior's leadership behavior, is moving in the focus of interest.

Definitions of leadership are so numerous that it is not possible to focus it on one definition and so are the included tasks like: motivating, delegating, organizing, coaching, consulting etc. The aspect which is missing in the list of tasks so far is the aspect of "... guarantee and satisfaction of emotional needs of employees like appreciation, contact, social affiliation ..." [4]. This underlines the importance of emotions: Hinterhuber [5] describes for example that change processes are mainly led by emotions and intuitions.

Under these aspects the understanding of leadership, its tasks and influences is beginning to change. Additional to leadership duties like coaching, delegating, motivating, communication, listening, deciding etc. consideration and management of emotions and emotional needs in the leader-membership inter- action is becoming more and more important in leadership research and practice [4] which is outlined in Figure 1.

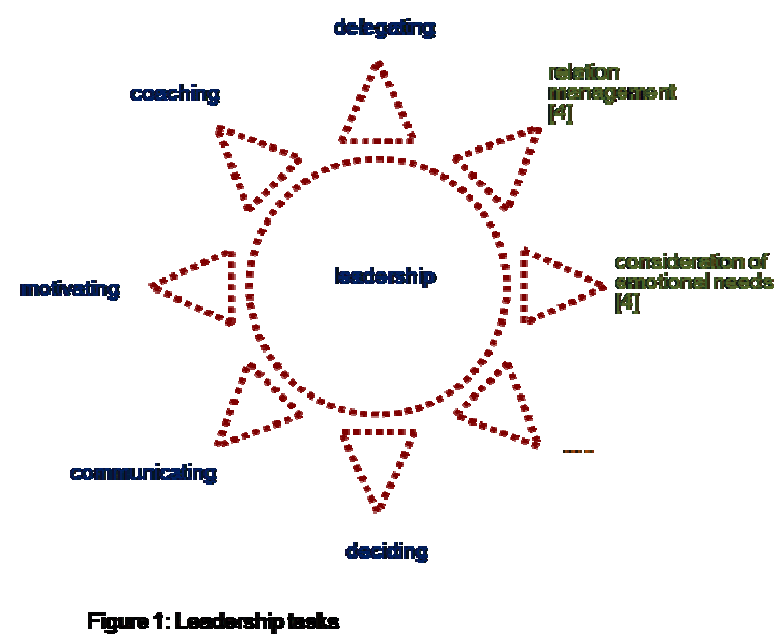

The perspective from which emotions are considered in the two existing studies is its influence on organizations. In professional life emotions can have an important impact. Supervisors for example can use emotions to motivate their employees or they can 
use them in a negative way to generate pressure in order to influence the employees' behavior [6]. Research results underline the impact and importance of emotions in the work context. Fischbach [7] has observed a positive coherence between the realized frequency of the supervisors' positive emotions and the employees' personal job engagement. In contrast to this Fischbach [7] could testify such a coherence between supervisors' negative emotions and the level of employees negative job satisfaction, motivation, the individual power of concentration and job performance [8]. Furthermore research results in the area of emotions and physical consequences prove that managers' leadership behavior is a very relevant reason for absence from work due to illness [9]. Moreover results from emotion-research show, that negative emotions like frustration and anger can influence the heart rate in a negative way with possible consequences of increasing stress experiences or blood pressure in contrast to positive emotions like appreciation or appraisal. Figure 2 shows heart rhythm characteristics under the influence of frustration/ anger and appreciation.

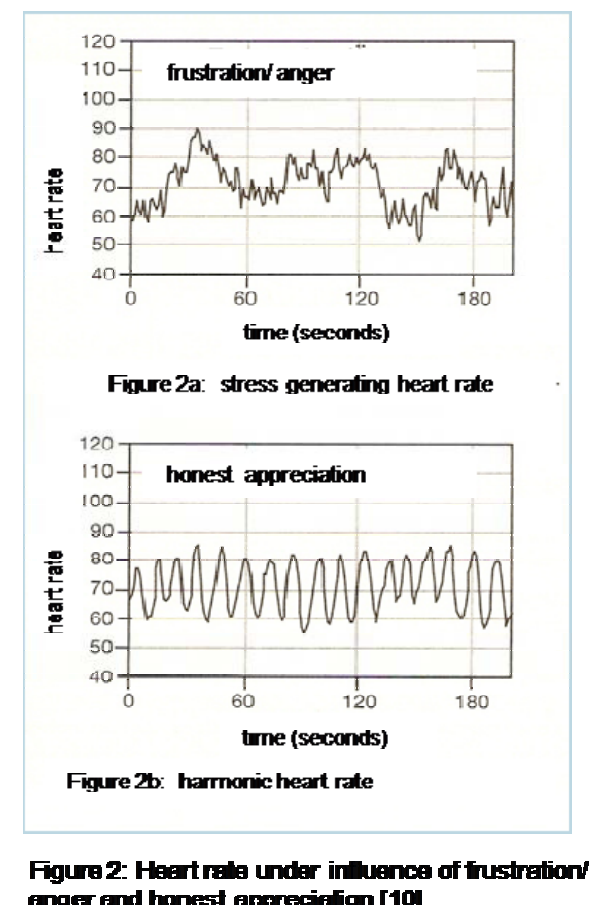

The purpose of the two underlying studies which were conducted in this context was to identify leadership behavior which causes positive emotions in order to make clear, which effects positive emotions in leadership contexts can have.
The results of both studies make clear that leadership behavior which causes positive emotions is connected with the aspects affiliation, appreciation, superiors support, praise and feedback, trust, positive leadership behavior, work climate, communication and openness.

Moreover both studies show that positive emotions caused by leadership behavior have positive impact on improvements of work related behavior (occupational health and safety) and on the improvement of teamwork.

\section{Experiment design}

The study in the automotive industry includes seven two hours lasting interviews with managers $(n=7)$ in that sector to identify leadership behavior which causes positive emotions in order to improve teamwork. The study in the energy industry in form of half-structured interviews with $n=37$ employees and $\mathrm{n}=32$ managers followed the aim to identify leadership behavior which causes positive emotions in order to improve employee-behavior in context of occupational health and safety.

\section{Critical evaluation}

By running a qualitative content analysis [11] the data were evaluated. The identified leadership behavior which causes positive emotions and well-being in the automotive sector from the managers' point of view are: emotional positive atmosphere (positive mood, positive humor), positive leader-employeerelationship, positive relationship between team members, appreciation, superiors' ability to be emphatic, trust, openness, communication in the leaderemployee-relation, feedback and praise. The aspects emotional positive atmosphere, positive leaderemployee and team-member-relations were mentioned by all interviewees $(100 \%)$ followed by feedback and praise $(85,7 \%)$. Moreover appreciation, ability to be emphatic, trust, openness and communication were mentioned by $71,4 \%$ of the superiors.

The results make clear that managers are aware of the emotions' importance, especially in social leaderemployee-interactions, and its influence in leaderemployee-relationships in organizational context.

The findings of the second study in the energy sector confirm the relevance of social leader-employeerelations (see Figure 3). The interviewed managers and employees specify social needs for appreciation, affiliation and teamwork, superiors' support and 
positive feedback as relevant to improve employeebehavior in context of occupational health and safety.

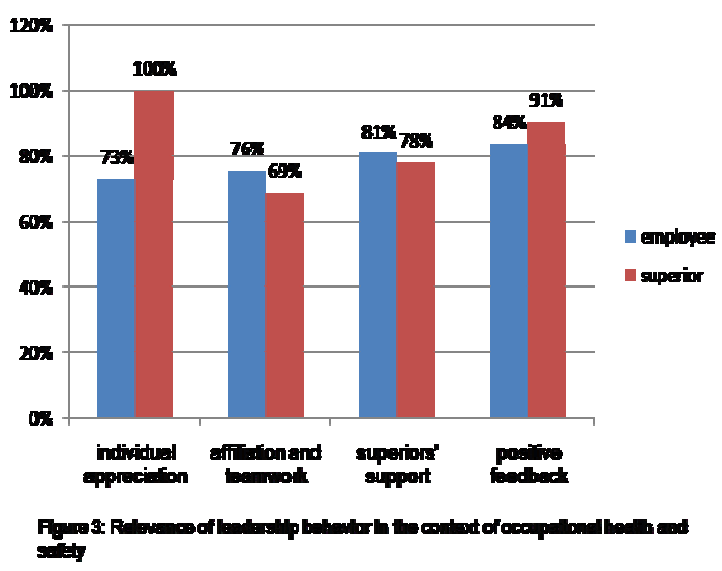

Even that the dimensions of both pilot studies are small the results give clear indication that the relevance of emotions in social interactions is very important from the point of view of the interviewed managers and employees. Moreover the thesis from the beginning of this article, concerning the relevance of emotions and emotional needs in the leadermembership interaction has been confirmed. But in this coherence it is important to hint on the fact, that besides this knowledge in the heads of managers and employees, numerous leadership, communication and behavior seminars are conducted in companies on the one hand. On the other hand nevertheless the number of mental illnesses in Germany has been rising [2]. The question which comes up in this context is: Why is the situation like it is? The assumption which has been made by the author in this context is that the applied realization in the organizational reality for managers is more difficult than it seems to be in a theoretical seminar. For that reason a further research project will be conducted to focus on these aspects.

\section{Conclusion and future-prospects}

In the first phase of a planned research project the reasons and impact of mental-emotional strain caused by leadership-behavior will be identified by running quantitative half-structured interviews in a first step and by conducting a survey on a quantitative basis in a next step. The second phase will include an experimental analysis with the method of eye-tracking movement and heart rate development. Both methods will identify in direct interactions, which behavior can cause mental-emotional strain and how this strain can be identified by analyzing eye-movement and heart rate development. The results will be transferred into a leadership training which sensitizes managers for emotional strain causing behavior and for the changes of eye-movements in these situations. With this knowledge managers will be able to realize emotional strained employees by their eye-movement and how to react appropriate to improve the situation.

\section{References}

[1] Stadler, P. (2006). Psychische Belastungen am Arbeitsplatz Ursachen, Folgen und Handlungsfelder der Prävention.

[2] BKK Gesundheitsreport (2009). Gesundheit in Zeiten der Krise.

[3] AOK (2009). AOK-Presse-Information. Februar 2009.

[4] Felfe, J. (2009). Mitarbeiterführung. Praxis der Personalpsychologie. Göttingen: Hogrefe Verlag.

[5] Hinterhuber, H. (2007). Leadership. Strategisches Denken systematisch schulen von Sokrates bis heute. In Achouri, C. (2009). Systemic Leadership. Oldenbourg Verlag, p. 40.

[6] Weinert, A. (2004). Organisations- und Personalpsychologie. Lehrbuch. Weinheim, Basel. Beltz-Verlag, p. 145, 277.

[7] Fischbach, A. (2009), ,Viele Mythen, erste Befunde und offene Fragen“, in Personalführung 6/2009, S. 36-47.

[8] Brief, A.P. et al. (1995). Cookies, disposition, and job attitude: The effects of positive mood-inducing events and negative affectivity on job satisfaction in a field experiment. Organizational Behavior and Human Decision Processes. April, 55-62. In: Weinert, A. (2004). Organisations- und Personalpsychologie. Lehrbuch. Basel. Beltz-Verlag, p. 145.

[9] Stadler, P., Strobel, G. (2006). Der Einfluss von Führungsverhalten auf die psychische Belastungssituation von Mitarbeitern.

[10] Childre, D. (2002). „Die Herzintelligenz entdecken“; S. 58, VAK-Verlag, Kirchzarten. In: Kinesiologie-Journal 04: Die Entdeckung der Herzintelligenz. Mit positiven Gefühlen im Herzen lebt es sich leichter und gesünder.

[11] Mayring, P. (2008). „Qualitative Inhaltsanalyse. Grundlagen und Techniken“. Beltz-Verlag. 